\title{
Food Intolerance in Children with Autism Spectrum Disorders
}

\section{Original Article}

\author{
Gamal Youssef Seleem Youssef ${ }^{1 \& 2^{*}}$. Khalid Kazim ${ }^{3}$, Hussain Hattawi \\ Phoniatrics Unit, Department of ${ }^{1} E N T$, Faculty of Medicine, Alexandria University, \\ Alexandria, Egypt, Department of ${ }^{2} E N T,{ }^{3}$ Laboratory, ${ }^{4}$ Immunology and allergy Unit, Dubai \\ Hospital, Dubai Health Authority (DHA), Dubai, UAE.
}

\begin{abstract}
Objectives: Genetic and environmental factors is suggested to play a role in the etiology of Autism spectrum disorders (ASD). The aim of the study was to investigate the link between specific food intolerances and autism spectrum disorders, by comparing the food Intolerance test in children with ASD and typically developing children without known food allergy or mental disorders.

Patients and Methods: This study included 100 patients diagnosed as ASD who attended the phoniatrics clinic in Dubai hospital in the period from Jun 2017 to Jun 2019. The control group involved 50 typically developing children. The diagnosis and severity of autism confirmed by childhood autism rating scale (CARS) and DSM V criteria. Food Intolerance test analyses IgG antibody levels to 222 specific foods to ascertain which food a person might be intolerant to. Results: The outcome measures were the percentage of children with elevated IgG in different food items and the mean level of IgG in each food item. The percentage of ASD children with positive food intolerance were $96 \%$ for milk, $94 \%$ for egg white, $96 \%$ for casein, $62 \%$ for gliadin, $74 \%$ for oat and $80 \%$ for wheat. There was a significantly higher level of IgG concentration $(\mathrm{U} / \mathrm{ml})$ in ASD than control group.

Conclusions: A high prevalence of food intolerance was identified in the ASD children. The results of the present study suggested the presence of food intolerance to multiple food items in children with ASD suggesting their possible roles in ASD etiology or symptomatology.
\end{abstract}

Key Words: Autism, autism spectrum disorders, diet therapy in autism, food allergy, food intolerance.

Received: 22 January 2020, Accepted: 27 June 2020

Corresponding Author: Gamal Youssef Seleem Youssef, MD, Department of ENT, Faculty of Medicine, Alexandria University, Egypt, Phoniatric, Dubai Hospital, Dubai Health Authority (DHA), Dubai, UAE. Tel.: 00971555518009, E-mail:dr.gamal@gmail.com

ISSN: 2090-0740, 2021, Vol.22

\section{INTRODUCTION}

Autism spectrum disorders (ASD) are a group of neurodevelopmental disorders characterized by impairment of reciprocal social interaction, nonverbal communication, and behavioral problems including restricted interests and repetitive behaviors ${ }^{[1]}$. ASD became a common public health problem with increased prevalence in the last few years. Although the etiology of ASD is mainly unknown, genetic and environmental factors are suggested to play a role in its development. Immunological disorders and allergy to foods are also reported in these children ${ }^{[2]}$.

The immune system produces immunoglobulin $G$ (IgG) antibodies in response to eating certain foods; the IgG combines with the food antigen to form immune complexes in the circulatory system that can accumulate in tissues. These immune complexes trigger an inflammatory response through the release of inflammatory cytokines, which increase the level of inflammation in the body, including the brain. Researchers suggest that the cause of passage of these food antigens to the circulation is increased permeability of intestinal endothelium in leaky gut syndrome, which was found to be associated with autism $^{[3]}$.

Studies suggest that ASD children may respond to specific kinds of food by the production of inflammatory cytokines. The cytokines from the ASD children exceeded those from non-autistic children after exposure to gluten or casein ${ }^{[4]}$. Researchers found that autistic patient's urine samples contained large amounts of peptides derived from the milk protein casein and the wheat protein gluten. These peptides react with opiate receptors in the brain, thereby mimicking the effects of opiate drugs ${ }^{[5-6]}$.

CNS Food-print Food Intolerance test analyses $\operatorname{IgG}$ antibody levels to 222 specific foods to ascertain which food a person might be intolerant to ${ }^{[7-8]}$.

In allergy/immunology practice and phoniatric/speech therapy practice, it became usual to be consulted for the 
evaluation of food allergy in an ASD child. Parents started to be eager to do the food intolerance testing as they have many questions about laboratory testing and dietary intervention measures. It is challenging to provide scientific information regarding therapy measures promoted by allied health practitioners, which often lack rigorous experimental validation. Although Food intolerance observed in children with neurodevelopmental disorders, the significance of this link is still under debate ${ }^{[9]}$.

\section{Objectives:}

The aim of the study was to investigate the link between specific food intolerances and autism spectrum disorders, by comparing the food Intolerance test in children with ASD and typically developing children without known food allergy or mental disorders. Furthermore, to correlate food intolerance severity to autism severity.

\section{PATIENTS AND METHODS:}

The study included 100 patients diagnosed as ASD who attended the phoniatrics or immunology clinics in Dubai hospital in the period from Jun 2017 to Jun 2019. The control group involved 50 typically developing children without known food allergy or mental disorders.

Exclusion criteria were autism secondary to genetic syndromes; epilepsy; celiac disease, and ASD children on dietary regimen.

The diagnosis of autism was carried out using the protocol of ASD assessment including; parent's interview, Checklist of ASD (CASD), clinical examination, diagnostic criteria of autism according to the Diagnostic Statistical Manual of Mental Disorders, Fifth Edition (DSM V) and childhood Autism Rating Scale (CARS) test. CASD is a 30-item parent or clinician checklist of autistic behaviors, set to the (DSM V), as a rapid test for diagnosis of $\mathrm{ASD}^{[1]}$. CARS test consists of 15 items rated on a 4-point scale. The CARS score can range from 15 to 60 points according to the severity of autism. The score categorized into nonautistic (15-29), mild to moderately autistic (30-36) and severely autistic (37-60 points).

CNS Foodprint Test Kits: 16 pads of microarray slides from the same lot that contain 222 food proteins per pad were used. Each pad contains its own calibrators and controls. Positive control results must fall between 70-130 $\mathrm{U} / \mathrm{ml}$ with a mean of $100 \mathrm{U} / \mathrm{ml}$.

The CNS Food-print Test results are revised and analyzed for several reactant food items and their level in $\mathrm{U} / \mathrm{ml}$. Reports of test results for each patient will show either elevated $(\geq 30 \mathrm{U} / \mathrm{ml})$, borderline $(24-29 \mathrm{U} / \mathrm{ml})$, or normal $(<24 \mathrm{U} / \mathrm{ml}) \mathrm{IgG}$ reactions in every tested food item.

\section{Statistical analysis:}

SPSS 20 (Statistical Package for Social Sciences) (SPSS Inc., Chicago, IL, USA) is used. Normal distribution of the data was tested using the Shapiro-Wilk test and most data was normally distributed, so we use the mean and parametric test as an Independent sample t-test to study significance between ASD group and control group. The independent sample Mann-Whitney U test was used for non-normally distributed data. Descriptive statistics expressed as frequency and percentage for nominal variables and the Pearson Chi-Square test were used to study significant differences between the 2 groups. A twosided $p<0.05$ was considered as statistically significant.

\section{RESULTS:}

The study included 100 patients with a diagnosis of ASD (82 males and 18 females). The mean age of the studied children was 5.3 years, and the age range was (2.4 -12 years).

The control group was 50 normal children (29 male and 21 female) with a mean age of 7.1 years and age range (4.2 -12 years).

ASD group children had a diagnosis of ASD and the CARS score mean was $35.6 \pm 5.1$. The severity of ASD was mild to moderate in 56 patients and severe in 44 patients.

Food-print test results for the ASD children were gathered, and the repeating elevated IgG results for each food $(>30 \mathrm{U} / \mathrm{ml})$ were counted and added together to see the number of times each type of food caused high IgG reaction. Foods that were elevated in $20 \%$ of the children or more were used. The reason for choosing frequencies 20 or above is that not every single elevated $\operatorname{IgG}$ causes a symptom; they must be frequent in most samples to be significant and to relate a condition to a symptom.

We studied the differences between the two groups by using 2 outcome measures: the percentage of children with elevated IgG in different food items and the mean level of $\mathrm{IgG}$ in each food item.

Table I and figure 1 show the percentage of ASD and control group patients with elevated IgG for different food items in each group. It revealed a significantly higher percentage of ASD patients with elevated IgG of egg white, casein, couscous, gliadin, oat, rice, bean, orange, Hazelnuts, pistachio, almond, and cashew in comparison to control group.

Table II and figure 2 show the differences in the mean level of $\mathrm{IgG}$ in each group and found that there was a significantly higher level of $\mathrm{IgG}$ concentration $(\mathrm{U} / \mathrm{ml})$ in ASD than the control group in egg white, milk, casein, 
couscous, gliadin, oat, rice, bean, orange and the 4 elevated nuts ( Hazelnuts, pistachio, almond, and cashew).

In the correlating level of $\operatorname{IgG}$, no correlation was found between the level of IgG and the severity of Autism or CARS score. There was a significant positive correlation between age and level of IgG for egg white, milk, casein, gliadin, oat, rice, Hazelnuts, pistachio, almond, and cashew. There was also a significant positive correlation between age and the total number of food items with elevated $\operatorname{IgG}$ in each patient $(\mathrm{r}=.001)$.

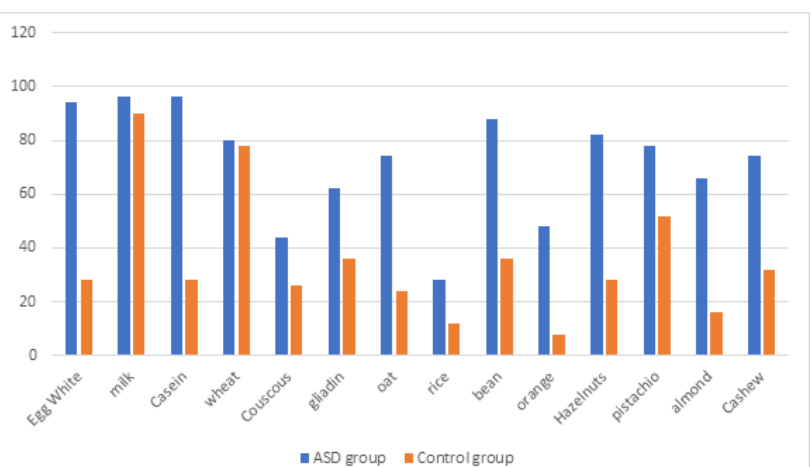

Fig. 1: Percent of ASD and control group patients with elevated IgG for different food items

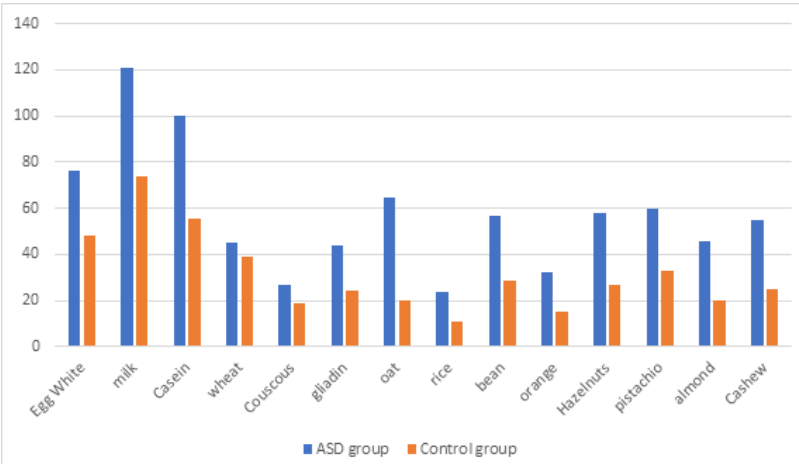

Fig. 2: Level of IgG concentration $(\mathrm{U} / \mathrm{ml})$ in $\mathrm{ASD}$ and control group

Table 2: level of $\operatorname{IgG}$ concentration (U/ml) in ASD and control group

\begin{tabular}{|c|c|c|c|c|c|}
\hline & Group & Mean IgG evel U/ml & Std. Deviation & T value & significance \\
\hline \multirow{2}{*}{ Egg white } & ASD & 76.0000 & 29.35261 & 5.452 & .000 \\
\hline & control & 48.5600 & 28.45057 & & \\
\hline \multirow{2}{*}{ Milk } & ASD & 121.3200 & 35.03386 & 7.606 & .000 \\
\hline & control & 74.6400 & 36.22479 & & \\
\hline \multirow{2}{*}{ Casein } & ASD & 99.8200 & 37.37535 & 6.964 & .000 \\
\hline & control & 55.4400 & 35.58615 & & \\
\hline \multirow{2}{*}{ Coscos } & ASD & 27.5800 & 20.11391 & 2.268 & .025 \\
\hline & control & 19.7400 & 19.63318 & & \\
\hline \multirow{2}{*}{ Wheat } & ASD & 45.0400 & 15.94683 & 1.832 & .069 \\
\hline & control & 39.8000 & 17.60450 & & \\
\hline \multirow{2}{*}{ Gliadin } & ASD & 44.0200 & 29.98551 & 4.146 & .000 \\
\hline & control & 24.2400 & 21.80485 & & \\
\hline
\end{tabular}

Table 1: Percent of ASD and control group patients with elevated IgG for different food items

$$
\text { ASD Group Control Group significance }
$$

\begin{tabular}{lccc} 
Egg White & 94 & 28 & $.000^{*}$ \\
milk & 96 & 90 & 0.161 \\
Casein & 96 & 28 & $.000^{*}$ \\
wheat & 80 & 78 & 0.304 \\
Couscous & 44 & 26 & $0.034^{*}$ \\
gliadin & 62 & 36 & $0.003^{*}$ \\
oat & 74 & 24 & $.000^{*}$ \\
rice & 28 & 12 & $0.038^{*}$ \\
bean & 88 & 36 & $.000^{*}$ \\
orange & 48 & 8 & $.000^{*}$ \\
Hazelnuts & 82 & 28 & $.000^{*}$ \\
pistachio & 78 & 52 & $.0001^{*}$ \\
almond & 66 & 16 & $.000^{*}$ \\
Cashew & 74 & 32 & $.000^{*}$ \\
\hline
\end{tabular}




\begin{tabular}{|c|c|c|c|c|c|}
\hline \multirow{2}{*}{ Oat } & ASD & 64.4600 & 41.12961 & \multirow[t]{2}{*}{7.203} & \multirow[t]{2}{*}{.000} \\
\hline & control & 19.9800 & 20.53518 & & \\
\hline \multirow{2}{*}{ Rice } & ASD & 24.6000 & 22.88575 & \multirow[t]{2}{*}{3.689} & \multirow[t]{2}{*}{.000} \\
\hline & control & 11.6600 & 13.44620 & & \\
\hline \multirow{2}{*}{ Corn } & ASD & 23.6400 & 16.07528 & \multirow[t]{2}{*}{.557} & \multirow[t]{2}{*}{.579} \\
\hline & control & 21.9800 & 19.32904 & & \\
\hline \multirow{2}{*}{ Bean } & ASD & 56.7200 & 22.39773 & \multirow[t]{2}{*}{7.409} & \multirow[t]{2}{*}{.000} \\
\hline & control & 28.5800 & 20.94901 & & \\
\hline \multirow{2}{*}{ Orange } & ASD & 32.5800 & 27.86917 & \multirow[t]{2}{*}{3.849} & \multirow[t]{2}{*}{.000} \\
\hline & control & 15.5400 & 20.09387 & & \\
\hline \multirow{2}{*}{ Hazelnut } & ASD & 58.7200 & 27.21114 & \multirow[t]{2}{*}{6.749} & \multirow[t]{2}{*}{.000} \\
\hline & control & 27.2000 & 26.45288 & & \\
\hline \multirow{2}{*}{ Pistachio } & ASD & 60.6600 & 34.73397 & \multirow[t]{2}{*}{5.109} & \multirow[t]{2}{*}{.000} \\
\hline & control & 33.4400 & 20.49008 & & \\
\hline \multirow{2}{*}{ Almond } & ASD & 46.2400 & 25.20587 & \multirow[t]{2}{*}{6.553} & \multirow[t]{2}{*}{.000} \\
\hline & control & 20.2600 & 17.28726 & & \\
\hline \multirow{2}{*}{ Cashew } & ASD & 55.5200 & 34.63066 & \multirow[t]{2}{*}{5.756} & \multirow[t]{2}{*}{.000} \\
\hline & control & 25.5800 & 17.34416 & & \\
\hline
\end{tabular}

\section{DISCUSSION}

The rising prevalence of autism spectrum disorder over the past decades has attracted researchers' attention, and considerable studies have been focused on its etiology and assumed that the etiologies of ASD are multifactorial, including environmental-genetic interactions $^{[10-12]}$.

The nature of the underlying etiopathogenesis of Autism Spectrum Disorder is still unknown and yet to be uncovered. Recently some researchers have suggested that food peptides that leak from gut to blood might induce immunological reaction or toxic effects on the central nervous system through interacting with neurotransmitters. The previous studies' results must lead us to hypothesize a relationship between food intolerance and $\mathrm{ASD}^{[5]}$. In the present study, we use the Food-print Food Intolerance test, which was developed and manufactured by Cambridge Nutritional Sciences in the UK, uses state of the art, clinically validated Elisa Based microarray technology to analyze 222 foods, including Gluten (Gliadin) and Casein from a $5 \mu \mathrm{l}$ blood sample. The test duplicates the results for 222 foods, and a mean result is taken, so preventing false-positive results being reported. The test includes positive and negative controls and uses standardized purified food antigens. The food print test is a validated laboratory test and used in many types of research in allergy and immunology disorders. To our knowledge, no published work used food-print test in ASD children.

The results of the present study suggested the presence of food intolerance to multiple food items in children with ASD. The IgG level was significantly higher in the ASD group in many food items, including milk, casein, gliadin, oat, rice, bean, orange, and nuts, in comparison to the control group, suggesting their possible roles in ASD etiology or symptomatology. Many children with ASD cannot properly digest peptides from proteins in their diet; peptides from milk, wheat, and eggs tend to be the most common problem $^{[9]}$.

Many types of grains, fruits, and vegetables have been modified genetically to withstand severe conditions. The peptides of the genetically modified food products are different from those that were available 10 or 20 years ago; for example, wheat has Gliadin as Gluten, which has been modified in several amino acids: Gliadin is now resistant to digestion. The same goes for all other grains, including rice, corn, oat, and nuts. Humans are consuming them directly and indirectly since its products have also entered animal and poultry feeds which affect animal and dairy products ${ }^{[13-15]}$. Genetically modified crops' consumption by humans leads to gut inflammation and openings in the gut's epithelial tight junctions (leaky gut syndrome) which allows passage of undigested peptides. Immunoglobulin $\mathrm{G}$ is produced to these food peptides and Inflammatory cytokines are released, which ultimately leads to a cascade of reactions and health problems such as brain function disorders ${ }^{[15]}$.

Cade's extensive study of 150 children with autism found that ASD children had IgG antibodies to gluten and casein, and this was significantly higher than control. Study on children with autism, who followed a Gluten Free Casein Free (GFCF) diet for 1-8 years, 
found that $81 \%$ of children improved significantly and large improvements were observed in social isolation, eye contact, mutism, learning skills, hyperactivity, stereotypic activity, and panic attacks ${ }^{[15]}$. A study of Vojdani (2017) ${ }^{[16]}$ found that antibodies against gliadin peptide were strongly reactive in a subgroup of $33 \%$ in the autism group.

Trajkovski et $a l^{[17]}$ found statistically significant higher plasma concentration of IgG antibodies against -lactalbumin, -lactoglobulin, and casein in participants with ASD. He concluded that the clinical correlation of positive allergy test results still unclear, but these children may represent a better candidate for dietary intervention.

Researchers have suggested "opioid-excess theory." It suggested that increased gut permeability for foodbased peptides might induce allergic reactions or cause pharmacologic effects. The incomplete digestion of casein and gluten-containing foods produce small peptide molecules that may function as exogenous opioids. These peptides bind to opioid receptors and are assumed to modulate opioid levels in the brain and react with areas of the brain that are involved in speech, sensory integration, and cognitive function ${ }^{[18-22]}$.

Topal E, et $a l^{[23]}$ found that two- thirds of the children with cow milk allergy have at least one psychiatric disorder, and this rate was higher than control. Vojdani ${ }^{[24]}$ found antibodies to neuron-specific antigens in children with autism and concluded a possible cross-reaction with encephalitogenic proteins from milk.

The positive correlation between age and level of IgG and the total number of food items with elevated IgG may indicate more IgG production with more food items introduced to the child's meal with the progress of age.

In the present study, it was found that a large number of control children have elevated IgG for many food items, which may indicate food intolerance is common across a wide range of health issues. One of the findings in this study was that $\operatorname{IgG}$ for nuts (Hazelnut, Pistachio, almond, and Cashew) was significantly high in ASD children and was normal in the control group. This finding may indicate the nature of the dietary habits of these patients and may help to predict when ASD children could benefit from dietary avoidance of these food items.

The results of the present study lead to speculation about the high prevalence of food intolerance in ASD children. Clarification of biology behind these antibodies' formation is needed. There is no evidence that increased food-specific IgG antibodies are correlated with the severity of $\mathrm{ASD}^{[25]}$. The data from this study must be interpreted with caution. The observed increase in $\operatorname{IgG}$ antibody formation in response to different food test items does not necessarily indicate sensitivity to it or any pathogenic role for antibodies to food items in the context of autism; but the elevated IgG may indicate elevated food antigens in the body, which may be themselves is the cause of pathology ${ }^{[26]}$. The validity of food intolerance tests still under investigation. The most recent studies stated that the production of IgG to different food components is a normal immunologic process and found in all healthy individuals. Some authors postulate that the development of IgG antibodies can cause food intolerance; others assumed that the development of such antibodies are linked to the development of food desensitization or tolerance ${ }^{[27-29]}$.

Compared to previous studies examining the relationship between food intolerance and autism, this study is unique in several ways. First, a shortage in the earlier studies was the small number of the patient group. In the present work, the IgG levels in 100 children with ASD were compared to a large cohort of healthy children. Second, previous reports have used IgG level to few food items, mainly Casein and gliadin products, while in the present study, we use a foodprint test, which is a comprehensive test that determines the level of IgG for 222 foods. The test duplicates the results, and a mean result is obtained, consequently preventing false-positive results from being reported. Furthermore, the diagnosis of Autism Spectrum disorder was accurately made by expert clinicians using DSM V criteria and standardized tests; however, in previous reports, it is unclear which test was used for the final diagnosis of autism.

A limitation of this study is that the control group was not investigated for other allergic or GIT disorders that may affect the levels of antibodies against antigens of the food intolerance test.

As such, the conclusions of this study should be considered preliminary, requiring further confirmation in more extensive and better-selected cohorts of patients and controls. An expert panel of the American Academy of Pediatrics has strongly recommended further investigation in these areas ${ }^{[30]}$.

Further studies concerning follow up of ASD children after specific diet plans, according to food intolerance test results are needed, to show the effect of intolerant foods free diet on autistic behavior severity and level of $\mathrm{IgG}$ after the diet plan. 


\section{CONCLUSION}

A high prevalence of food intolerance was identified in ASD children. The results of the present study suggested the presence of food intolerance to multiple food items in children with ASD suggesting their possible roles in ASD etiology or symptomatology. There is no evidence that increased food-specific IgG antibodies are correlated with the severity of ASD.

\section{CONFLICT OF INTEREST}

There are no conflicts of interest.

\section{REFERENCES}

1. Harris JC. New classification for neurodevelopmental disorders in DSM-5. Current Opinion in Psychiatry. 2014 Mar;27(2):95-7.

2. De Theije CG, Bavelaar BM, Lopes da Silva S, Korte SM, Olivier B, Garssen J, Kraneveld AD. Food allergy and food $\square$ based therapies in neurodevelopmental disorders. Pediatric Allergy and Immunology. 2014 May;25(3):218-26.

3. d'Eufemia P, Celli M, Finocchiaro R, Pacifico L, Viozzi L, Zaccagnini M, Cardi E, Giardini O. Abnormal intestinal permeability in children with autism. Acta paediatrica. 1996 Sep;85(9):1076-9.

4. Rao AN, Minakshi K, Sabyasachi G, Kumar VS. Food allergy investigations and its significance in Autism Spectrum Disorders. International Journal of Pharma and Bio Sciences . 2010;1(4):59. ISSN 0975-6299 www.ijpbs.net Biochemistry.

5. Reichelt KL, Knivsberg AM, Lind G, Nødland M. Probable etiology and possible treatment of childhood autism. Brain Dysfunction. 1991;4:308-19.

6. Reichelt KL, Knivsberg AM. Can the pathophysiology of autism be explained by the nature of the discovered urine peptides?. Nutritional Neuroscience. 2003 Jan 1;6(1):19-28.

7. Leung J, Crowe SE. Food allergy and food intolerance. World Rev Nutr Diet 2015;111:76-81.

8. Lavine E. Blood testing for sensitivity, allergy, or intolerance to food. CMAJ 2012 Apr ;184(6):666-68. doi: 10.1503/cmaj.110026.

9. Harium J. Food Allergy and Autism Spectrum Disorders: Is There a Link? Current Allergy and Asthma report. 2009; 9: 192-201. ISSN 1529-7322.
10. Newschaffer CJ, Croen LA, Daniels J, Giarelli E, Grether JK, Levy SE, et al. The epidemiology of autism spectrum disorders. Annu Rev Public Health. 2007;28:235-58.

11. Landrigan PJ. What causes autism? Exploring the environmental contribution. Current opinion in pediatrics. $2010 \mathrm{Apr} ; 22(2): 219-25$.

12. Maffini MV, Neltner TG. Brain drain: the cost of neglected responsibilities in evaluating cumulative effects of environmental chemicals. J Epidemiol Community Health 2015 May;69(5):496-9.

13. Premanandh J, Maruthamuthu M, Sabbagh A, Al Muhairi S. Prevalence of genetically modified foods (GM foods) in the United Arab Emirates. Food Control 2012;25:10-12.

14. Klümper, W, Qaim, M. A meta-analysis of the impacts of genetically modified crops. PloS one 2014;9(11), e111629. https://doi.org/10.1371/journal. pone. 0111629 .

15. Cade R, Privette M, Fregly M, Rowland N, Sun Z, Zele V, Wagemaker H, Edelstein C. Autism and schizophrenia: intestinal disorders. Nutritional Neuroscience. 2000 Jan 1;3(1):57-72.

16. Vojdani A, Vojdani E. Gluten and non-gluten proteins of wheat as target antigens in autism, Crohn's and celiac disease. Journal of cereal science. 2017 May 1;75:252-60.

17. Trajkovski V, Petlichkovski A, Efinska-Mladenovska O, Trajkov D, Arsov T, Strezova A, Ajdinski L, Spiroski M. Higher plasma concentration of foodspecific antibodies in persons with autistic disorder in comparison to their siblings. Focus on Autism and Other Developmental Disabilities. 2008 Sep;23(3):176-85.

18. Deufemia P, Celli M, Finocchiaro R, Pacifico L, Viozzi L, Zaccagnini M, Cardi E, Giardini O. Abnormal intestinal permeability in children with autism. Acta paediatrica. 1996 Sep;85(9):1076-9.

19. Knivsberg AM, Reichelt KL, Nødland M. Reports on dietary intervention in autistic disorders. Nutritional Neuroscience. 2001 Jan 1;4(1):25-37.

20. Shattock P, Kennedy A, Rowell F, Berney T. Role of neuropeptides in autism and their relationships with classical neurotransmitters. Brain Dysfunction. 1990 Nov;3:328-45. 
21. Panksepp J. Brain opioids: A neurochemical substrate for narcotic and social dependence. Progress in theory in psychopharmacology. 1981;1:149-75.London, UK: Academic Press.

22. Knivsberg AM, Reichelt KL, Nodland M, Hoien T. Autistic Syndromes and Diet: a follow $\square$ up study. Journal of Curriculum Studies. 1995 Sep 1;39(3):22336.

23. Catal F, Topal E, Soylu N, Ozcan OO, Celiksoy $\mathrm{MH}$, Babayiğit A et al. Psychiatric disorders and symptoms severity in preschool children with atopic eczema. Allergologia et immunopathologia $2016 \mathrm{Mar}$ 1;44(2):120-4. doi: 10.1016/j.aller.2016.03.001.

24. Vojdani A, Campbell AW, Anyanwu E, Kashanian A, Bock K, Vojdani E. Antibodies to neuron-specific antigens in children with autism: possible crossreaction with encephalitogenic proteins from milk, Chlamydia pneumoniae and Streptococcus group A. Journal of neuroimmunology. 2002 Aug 1;129(12):168-77.

25. $\mathrm{Ng} \mathrm{M}$, de Montigny JG, Ofner M, Docé MT. Environmental factors associated with autism spectrum disorder: a scoping review for the years 2003-2013. Health promotion and chronic disease prevention in Canada: research, policy and practice 2017 Jan;37(1):1.

26. Kelso JM. Unproven diagnostic tests for adverse reactions to foods. The Journal of Allergy and Clinical Immunology: In Practice. 2018 Mar 1;6(2):362-5.

27. Gocki J, Bartuzi Z. Role of immunoglobulin G antibodies in diagnosis of food allergy. Advances in Dermatology and Allergology/Postępy Dermatologii Alergologii 2016 Aug;33(4):253.

28. Sivanandha NK, Nalini N, Banupriy AL, Palaniswam YM. Prevalence of food allergens in different age groups in and around pollachi, coimbatore, Tamil nadu, South India. International Journal of pharma and BioScience 2017; 8(1):652-67. 10.22376 ijpbs.2017.8.1.b652-667.

29. Samsam M, Ahangari R, Naser SA. Pathophysiology of autism spectrum disorders: revisiting gastrointestinal involvement and immune imbalance. World journal of gastroenterology 2014 Aug 7;20(29):9942-51.

30. Carr S, Chan E, Lavine E, Moote W. CSACI position statement on the testing of food-specific IgG. Allergy, Asthma \& Clinical Immunology. 2012 Dec;8(1):12. 